\title{
LA REPÚBLICA DE COELEMU Y EL MALESTAR EN LA NACIÓN. CODIFICACIONES LOCALES EN LA NUEVA PROVINCIA DE ANDRÉS GALLARDO
}

\author{
THE REPUBLIC OF COELEMU AND THE NATION'S UNREST. \\ LOCAL ENCODINGS IN ANDRÉS GALLARDO'S LA NUEVA PROVINCIA
}

\author{
Mario Verdugo \\ Universidad de Talca. Talca, Chile \\ verdugoarellano@gmail.com
}

\begin{abstract}
Resumen: El artículo indaga en la configuración del espacio y, específicamente, del territorio periférico en la novela La nueva provincia de Andrés Gallardo, publicada originalmente en 1987 y reeditada en 2015. A partir de las propuestas autonómicas de Gaspar Cifuentes y los demás personajes, se plantea la existencia de un operar diferenciado y clausurado que compromete la univocidad del modelo hegemónico de espaciamiento y genera relaciones anómalas entre centro y periferia. Pese al reducido contexto de emisión en que despliegan su sistema provinciano, los autonomistas de Coelemu logran trascender la visión dominante que acostumbra reducirlos a mero rezago, microcosmos epigonal o eco distante de lo acontecido en la metrópoli chilena.
\end{abstract}

Palabras clave: Narrativa chilena, novela chilena y territorio, centralismo literario, provincia y nación, literatura regional.

\begin{abstract}
The article explores the configuration of space and, specifically, of the peripheral territory in Andrés Gallardo's novel La nueva provincia, originally published in 1987 and reissued in 2015. Based on Gaspar Cifuentes' autonomous proposals, and the other characters, a differentiated and closed way of acting that compromises the uniqueness of the hegemonic model of spacing, creating anomalous relationships between the center and the periphery, is suggested. Despite the reduced emission context where they deploy their provincial system, the autonomists from Coelemu manage to transcend the dominant view that used to reduce them to a mere lag, an epigonal microcosm or a distant echo of what happened in the Chilean metropolis.
\end{abstract}

Keywords: Chilean narrative, Chilean novel and territory, literary centralism, province and nation, regional literature.

Recibido: 31.03.2016. Aceptado: 14.06.2016. 


\section{Introducción}

UTOR QUe EN FUnCIÓn de sus singularidades "corre el riesgo de ser perAmanentemente redescubierto" -a decir de Adriana Valdés (2007: 9)-, Andrés Gallardo ha tenido como escenario preferente de sus relatos a los pueblos y ciudades de provincia. A menudo en conflicto con los estereotipos que orientan la representación de estos espacios, y casi siempre convirtiendo en parte de la diégesis a los materiales ad hoc heredados de la tradición literaria -sobre todo la ligada al criollismo-, una línea temática de indiscutible continuidad puede seguirse desde Historia de la literatura y otros cuentos (1982), hasta Tríptico de Cobquecura (2007), pasando también por Cátedras paralelas (1985), Obituario (1987) y Las estructuras inexorables del parentesco (2000).

Se diría que aquellos materiales preformados con los cuales la narrativa gallardiana tiende a carearse una y otra vez, sin descontar por cierto a la novela que se abordará enseguida, guardan relación con un extendido modelo de espaciamiento ${ }^{1}$, cuyo efecto es la verticalización axiológica del binarismo centro-periferia en una latitud de alcance subnacional. Sea en el plano de los hechos estrictamente fictivos, sea en universos socioculturales más amplios, dicho modelo acaba consagrando la superioridad del primer término y el intrínseco desmedro del segundo. La metrópoli, beneficiándose de este ubicuo estatus geográfico, no sólo despunta como centro político-administrativo sino además como el único horizonte de realización individual y colectiva, como el moderno lugar de llegada, como el "arriba" que monopoliza las imágenes de prestigio, mientras que los espacios periféricos o provincianos quedan circunscritos a un "abajo" por lo general despreciable y estático. Realidad de suyo contraejemplar, la provincia cobra asimismo una posición excepcional dentro de la común politicidad que la narratología atribuye a las configuraciones espaciales, asomando entonces como algo que está realmente ahí, en la realidad factual, y que se encuen-

${ }^{1}$ Espaciamiento es el concepto alternativo con el que Culler explica la différance derridiana (Culler, 1984: 89), y sirve también para designar tanto una ordenación preexistente como un acto de ordenar, tanto una diferencia pasiva como una simultánea diferenciación, un nuevo mapa. El propio Derrida utiliza el vocablo francés correspondiente: espacement. Culler lo emplea en inglés como spacing y en la versión española aparece precisamente como "espaciamiento". 
tra disponible para el calco mimético de manera aproblemática, es decir, sin que se hagan patentes las actividades textuales codificadas ni la violencia simbólica que desde luego intervienen en su construcción.

En el planteamiento de Bajtín, por ejemplo, la “pequeña ciudad burguesa" es nada más que un "trasfondo contrastante para las series temporales vitales y enérgicas", un ámbito en cuyas "casitas y calles somnolientas" nunca se registran verdaderos sucesos, y al que los novelistas suelen acudir tan sólo por su condición cronotópica de "tiempo auxiliar" (Bajtin, 1989: 388). Al teñirse de una valoración negativa, fruto de su desajuste con la modernidad capitalina vertiginosa y deseable, el espacio provinciano consigue atraer anatemas de toda clase, inclusive recurrentes entre quienes cuestionan las localizaciones epistémicas. De "segregación amurallada" y "particularismo estrecho" hablará Césaire (2006: 13-14). La vanidad del pueblerino, convencido de que su terruño es el ónfalo del mundo, será objeto de repudio para José Martí (Achugar, 1996: 850). Y Gramsci fustigará al redactor "mediocre, ignorante y quisquilloso", descolgado de los sucesos nacionales e internacionales, que campea en la escena cultural de las aldeas y urbes menores de Italia (Gramsci, 1967: 121). La consideración de la provincia como un orden dado, estacionario y corrupto, en el que no cabe hacer mención de intertextualidades o perspectivas interesadas, reaparece ocasionalmente también en la crítica literaria al momento de juzgar aquellos textos que toman a estos conglomerados como tema. Así habría de ocurrir, sólo por poner un par de casos extremos, con Raúl Silva Castro y Ricardo Latcham cuando ponderan los méritos de La señorita CortésMonroy de Januario Espinosa (1928), una novela cuyo narrador sobresale por el talento para "coger" y "pintar" objetivamente a la provincia "sombría, alcohólica y precaria” (Latcham, 1930: 79), o por su "sangre fría para permanecer largas horas al borde del pozo nauseabundo, la provincia donde se pudren los deseos" (Silva Castro, 1928: 227).

Según podrá observarse más abajo, la obra de Gallardo introduce otras escalas, otros puntos de vista y otras jerarquías geográficas. El espacio en cuestión se desnaturaliza y complejiza; deja de ser una realidad a priori e ingresa al relato como una materia ya recortada por discursos precedentes. Tales alteraciones se concretan dentro de la misma trama convencionalizada por el modelo hegemónico, aunque retorciéndola y poniéndola al descubierto. Si la representación degradatoria de la provincia ha llegado a ser 
dominante en el marco de la literatura chilena y más allá ${ }^{2}$, Andrés Gallardo la reescribe como si se tratase de un tópico, esto es, como un "cliché" o una "fórmula" que se estandariza y se mantiene pertinazmente en la tradición pero que todavía es susceptible de nuevas atribuciones y distribuciones de sentido (López Martínez, 2007).

\section{Local / No local}

La explícita asunción del tópico, y su simultánea puesta en crisis, se instaura ya a partir del nombre de la novela que Gallardo publica en 1987: La nueva provincia. El paratexto estatuye la doble suerte que aguarda al espacio subnacional: consenso, porque sigue siendo, pese a todo, "provincia", y disenso también, por tratarse de otra cosa, una cosa "nueva", potencialmente disruptiva. No faltan argumentos para postular que la novela entera gira en torno al posible estallido del molde preexistente, tanto que a la vuelta de los hechos narrativos llegará a ser inoficioso determinar cuál posición ha triunfado, pues lo definitorio es que la lucha se ha dado cita en un escenario antes inmutable 3 .

La acción ocurre en Coelemu, espacio ficcional que remite por supuesto a una localidad empírica situada en el sur de Chile. Allí, un grupo de vecinos busca romper con la secundariedad que el pueblo ha padecido merced a los poderes del centro, ya se trate del influjo santiaguino ("la codicia insaciable de la capital", 10), ya de sus delegaciones regionales (los "tentáculos

Eso es lo que se conjetura en el prólogo a una antología poética publicada en Concepción: la provincia en Chile como un "ámbito residual, habitado por un desecho humano incapaz de romper con la dependencia perversa". En el caso penquista, la imagen se ha visto reactualizada por caracterizaciones "negativas de las formas que asume la sociabilidad y el espacio físico en que se (des)integra la ciudad” (Alonso, Mestre, Rodríguez y Triviños, 1989: 12-13). La hipotética dominancia no es óbice, por supuesto, para que existan visiones disímiles y hasta contrapuestas, como lo ilustran los cantos laudatorios al paisaje local y a la vida provinciana en la poesía lárica o en los versos nacionalizantes de principios del siglo XX.

${ }^{3}$ Estas ambivalencias pueden abordarse, también, conforme a la naturaleza transideológica de las inversiones irónicas. Para Hutcheon (2000), la ironía es menos un instrumento retórico fijo que un acontecimiento, una escena que acontece cuando un intérprete atribuye una motivación operativa, una intención de ironizar. A juicio de Hutcheon, no se puede dar nunca por sentado que la escena acontezca efectivamente, ni mucho menos se puede determinar cómo será leída, puesto que su naturaleza transideológica la torna disponible tanto para conservadores como para rebeldes, tanto para la ratificación de tópicos como para la deconstrucción de posiciones autoritarias y unívocas. 
ñublense y penquista”, 10). Las consecutivas y cada vez más ambiciosas propuestas autonómicas de Gaspar Cifuentes y sus secuaces, junto al repertorio de sus estrategias orientadas al acopio de un espesor simbólico para el reordenamiento territorial, delinean lo que llamaremos un sistema provinciano, definido como un modo de autoorganización y construcción propia de la realidad, una configuración sui géneris que sin negar la existencia del mundo circundante, opera de manera diferenciada y clausurada, con arreglo al estado de información que surge de su código específico, aquel que fija como valor positivo a lo local y como valor negativo a lo no local. El valor positivo, en palabras de Luhmann (2000: 25), designa la capacidad de enlace de la operación del sistema; gracias a esa capacidad de enlace, el sistema está facultado para empezar algo. De esta guisa, la realidad de la provincia sólo puede ser un correlato interno a la operación del sistema, y de ninguna manera una cualidad que le adviene. Lo primordial es que el sistema provinciano se haga diferente del entorno, al que sin embargo puede acoplarse a través de una red de campos programáticos que tematizan las estimulaciones externas o heterorreferencias.

Nuestra figura tenderá a la clarificación al traer el auxilio de un ejemplo probado: el análisis luhmanniano de los medios de masas. Para el autor alemán, los mass media constituyen un logro evolutivo de la sociedad en su proceso de diferenciación, por muy atingentes que sean las denuncias de un pensamiento crítico atento al rol manipulador desempeñado por la industria cultural. Los medios son de acuerdo a Luhmann la medida de sí mismos: actúan en respuesta a su peculiar codificación binaria, cuyo basamento es el par informable / no informable. Cualquier dato externo debe pasar por ese tamiz antes de integrarse a la realidad mediática, donde sólo circula aquello que ha sido reprocesado según el código, aquello que ha sido convertido en "tema" de comunicación. Del entorno al sistema hay más que un transporte, como bien lo ilustra Torres Nafarrate (2000: XX): "Ni la información ni la representación que se hace en los medios sobre el arte, es arte; ni la información ni la representación sobre la ciencia, es ciencia; ni la información ni la representación sobre la política, es política”. Los estímulos del entorno, no siendo determinante su procedencia, ni si son o no "verdaderos", afectan a la televisión o los periódicos únicamente si sortean el umbral que los metamorfosea, bajo una lista de criterios o selectores que en el campo de las "noticias y reportajes" incluye al "conflicto", el 
"escándalo", la "contravención de las normas" y el "acontecimiento único" (Luhmann, 2000: 44-46). Se comprende así que la clausura no conlleva un sustraerse a los demás sistemas sociales, puesto que el acoplamiento con ellos es precisamente la función encargada a los campos, entre los cuales despuntan las citadas noticias junto al "entretenimiento" y la "publicidad". Los campos propenden a la diversificación de las heterorreferencias (arte, política, ciencia, etc.), mientras que el código acredita el operar autónomo, erigiéndose como la unidad de la diferencia sistémica. Tiempo queda aún para continuar discutiendo el problema de la verdad en los medios, pero el corolario de esta teoría no puede sino desalojar tal problema, inesencial para una selectividad que se restringe a las condiciones de lo informable y que, de abocarse a virtualidades ajenas, lo hará tematizándolas, es decir, mirándolas con su propio prisma, conjurándolas por medio de su propio filtro.

La construcción provincial de la realidad emula el desenvolvimiento de los mass media, aunque en las peripecias de su ensamblaje multiplique las alertas de un mecanismo defectuoso o desajustado, en franco riesgo de rendirse como tantas veces ante las presiones del ridículo. Si el sistema mediático hace gala de un influyente rendimiento hacia afuera de sus límites, incentivando la adopción por otros sistemas de su misma operatividad acelerada, con lo que acaba instalando en toda la sociedad un horizonte cognitivo empujado a la constante renovación (perecibilidad de los temas, hipersensibilidad frente a los cambios, necesidad de una memoria ligera que no sujete las acciones), el sistema provinciano exhibe a cada instante la miseria de sus outputs, la respuesta -cuando existe- desdeñosa de un entorno que no parece darse por enterado, o que se obstina en recodificar a la provincia como la antítesis de la dinámica que los medios fundan y desperdigan, como un estado estacionario del mundo, una "normalidad imperturbable" (Luhmann, 2000: 115) . Hacerse sistema es desechar la medida de los otros, desmesurarse, actuar bajo la regencia de un patrón autogenerado. Y es esa la buena nueva que los paladines de Coelemu, a

${ }^{4}$ Para Luhmann los medios mantienen a la sociedad en vigilia, renovando su disposición a las sorpresas e irritaciones. Nada más opuesto, por lo tanto, a las características del espacio provinciano en su conformación normalizada. En resumidas cuentas la provincia encarna o ilustra aquello que los medios se encargan de silenciar. 
pesar de las admisibles fallas de su maquinaria, proclaman en un espacio antes sometido íntegramente, unánimemente al procesamiento afuerino.

\section{El sistema provinciano}

La novela arranca con una reunión en que se justiprecian los méritos de diversos espacios, transitando desde el lamento compartido ("antes en provincia se vivía mejor", 7) hasta el localismo más pronunciado y la exasperación anticentralista, para desembocar en un brindis contemporizador que no mezquina las apologías: "Santiago es una gran ciudad, es la capital de la Madre Patria [...] Concepción es la capital cultural de la República de Chile [...] Chillán es la cuna noble de nuestra historia" (8). El punto de arranque refrenda ya la toma de conciencia que los personajes manifiestan acerca de las asimetrías geográficas. Cifuentes, previo al brindis final, ha hecho el arqueo poco feliz de su terruño "pobre, chico y desconocido" (8), comprimiendo en este enunciado la variada traza del discurso corriente. Porque las regularidades del tópico no escasean en la novela, sino que abundan y por su misma abundancia fortifican la dramaticidad del relato, el vaivén entre la conservación del modelo y su quebrantamiento por obra del disturbio identitario que germinará acto seguido. La nueva provincia tiene también sus actores minusválidos, su infraestructura retrasada, sus hombres y mujeres escapistas, su endemia topofóbica 5 . El intelectual de baja estofa, bosquejado por Gramsci, resurge en Nelson Arias, profesor de liceo, quien afronta la tarea de justificar culturalmente la iniciativa emancipadora:

Arias [...] le había tomado el gusto a ver sus cositas publicadas en los suplementos culturales de los diarios. En Chillán sus crónicas sobre la vida

${ }^{5} \mathrm{El}$ tópico provinciano es factible de descomponer en una serie de regularidades que giran en torno al sedentarismo como meollo de la degradación, vale decir, la ineptitud de los sujetos no capitalinos para sumarse a los patrones de sociabilidad visibles en la metrópoli moderna. Pero también podría hablarse de minusvalías (condición del aldeano miope, paralítico o alcohólico), los retrasos (exhibición del aspecto provinciano como un espectáculo cómico, proclive además al arcaísmo y al remedo), las huidas (relación vicarial con el centro que se corporiza como ensueño compensatorio, como conciencia admirativa que prohíbe la negociación entre identidades o a veces desemboca en laboriosos procesos de resocialización) y las topofobias (apreciación de repulsa a raíz de una estadía en la provincia, en una escala que abarca desde el mero desprecio intelectual hasta la manifestación de reacciones sintomáticas a un nivel físico) (Verdugo, 2010). 
de los arrieros y las hazañas míticas de los bandidos habían alcanzado cierta notoriedad. [...] En extensos poemas, Arias describía con lujo de detalles la flora local, con lo que, explicaba en prosa, realzaba la dimensión eglógica de la identidad coelemana. Por alguna razón, entre Nelson Arias y Primavera Cifuentes se creó una corriente de antipatía que tocaba a menudo la hostilidad. A sus amigos poetas, Arias le comentaba con desdén el vanguardismo infantil y vacuo de Primavera y a sus amigos escribientes los instaba a cultivar una literatura centrada en la tierra y sus fuerzas milenarias. Primavera y sus amigos poetas se mataban de la risa con la retórica decimonónica de Arias y sus amigos escribidores publicaban un folleto mimeografiado rebosante de textos experimentales y de diatribas [...] contra la literatura reaccionaria de Arias (35).

El profesor asume desde sus vagas competencias la misión que Gaspar Cifuentes lidera en el plano político, y es la hija de este último, Primavera, la que ejercita una postura radicalmente opuesta, de suyo satisfecha con su aperturismo heterorreferencial: "Miraba alrededor, pensaría en Macondo, pensaría en Comala, pensaría en Los pasos perdidos [...], se limitaba a decir 'tremenda cosa', murmuraba 'pueblo de mierda' y se ponía a hablarle a su papá de lo real maravilloso" (54). Esta batalla por el poder simbólico ${ }^{6}$, a sugerencia del narrador, no se inclina necesariamente hacia alguna de las dos posturas, pues ambas se entremezclan, co-implican y seducen, lo cual se presentiza en las repetidas "traiciones" de Arias al interrumpir la redacción del poema épico La Coelemana y al querer publicar sus manuscritos en "una editorial de Santiago" (89), o en lo frágil de la prédica adversaria, que pese a su repudio del "ñoño intento de justificar la opresión y continuidad de un orden decadente con una metrificación obsoleta" (77), suele aflojar y hasta ceder ante el soborno nada suntuoso de las comidas y bebidas autóctonas.

Con Primavera a la cabeza, los jóvenes estudiantes de Coelemu son los que experimentan el deseo de huir. Huir del espacio material y de todo lo que a él es contiguo, para aproximarse con mayor o menor éxito al vertiginoso ritmo moderno, siquiera en la cercana Concepción, donde "el proceso revolucionario se podría vivir con más intensidad” (93). La mitigación de

\footnotetext{
${ }^{6}$ La disputa, en la óptica de Primavera Cifuentes, se da entre un lugar calcable (propicio al anacronismo criollista) y un lugar literaturizable (legítimo para una narrativa del boom a la que se estima contemporánea).
} 
ese ritmo en provincias, o su implementación tardía, su retraso, campea en la secuencia que narra la llegada del cine a la zona; hito que habría de significar un impulso para el proyecto provincializador pero que en la práctica se observa como un rezago imitativo, con una vieja película en cartelera y un cantante de tercera categoría a cargo del espectáculo inaugural, en vista de las excusas que ha presentado, primero, el "gran cantante mexicano Pedro Vargas", y luego, quien Vargas recomienda como sustituto, el "notable cantante chileno Hernán Paredes y sus Mariachis" (51). Desaire nacional y desaire extranjero se hacen sentir casi al unísono, en beneficio de una imagen peyorativa cuyo abanico de expresiones puede abrirse inclusive a un vínculo espacial-actorial de tipo topofóbico (Verdugo, 2010), aquí verificable en el acompasado declive de Gaspar Cifuentes y su pueblo, un declive que, eso sí, no reviste la usual relación causa-efecto: "Coelemu parecía achicarse. Las casas se despintaban, los caminos cedían al deterioro [...], las vides y las viejas chacras como que se apestaban cada día más por el abandono. [...] El tiempo seguía pasando sin perdonar. Cifuentes se ponía inevitablemente más viejo" (33).

Pero al lado de estas regularidades hallamos el disenso que ya se insinúa ab ovo. Cifuentes, secundado por Meneses y Plasencia, concreta el acto que funda la diferencia del sistema provinciano en el año del bicentenario de Coelemu. Un 18 de septiembre, la "Nueva Provincia" nace como "patria libre" (18), mediante un enunciado realizativo cuya fuerza ilocucionaria tiene un equivalente en la autoproducción sistémica.

Señores, basta ya de prepotencia penquista, basta ya de cantos de sirena chillanejos; ya tenemos más que suficiente con el centralismo impersonal santiaguino. Señores, con serena responsabilidad, anclado en la historia y con la mirada confiada en el futuro, me atrevo, por fin, a declarar lo que por años he llevado oculto en mi corazón: Coelemu está maduro para convertirse en provincia, la provincia de Coelemu, capital Coelemu (17).

La performatividad del fragmento precedente promociona al referido conglomerado a un rango superior del que lo mantenía, en el nivel administrativo, por debajo del término "provincia”. Su eficacia apunta a un contexto de emisión muy estrecho, aquel que forman solamente los tres fundadores, y no aparenta repercutir ni precisar de repercusiones en el entorno. 
Debe inferirse que el sistema de veras cuaja, que Cifuentes ha sabido hacer una provincia con palabras, pues así lo creen al menos Meneses y Plasencia. Toda la realidad del sistema será en lo sucesivo su propia operación, amenazada, claro está, por las sobreestimulaciones exteriores, y tan reducida en sus proporciones que será blanco fácil de la ironía y el renovado desdén.

Del impacto tenue que la declaración autonomista concita en el exterior hay un crecido número de evidencias. Entre ellas un par: los diarios capitalinos y regionales omiten la noticia o la denigran como broma o nota curiosa, extremando su negligente recepción hasta cambiar el nombre del pueblo por el de "Copiulemu" (47); y los personeros enviados por el gobierno central, fieles al realismo que emana de su código, tematizan la intentona con un tono no menos denigrante y burlesco: "ustedes están locos" (119), "así es que es verdad que ustedes toman en serio esa huevada de la nueva provincia" (38). La dimensión exigua del sistema se corrobora además en su no coincidencia con el espacio ya de por sí exiguo en el que emerge. Tampoco el resto de la población coelemana se hace partícipe del cambio de estatus, y sólo "el triunvirato" que ha asumido "el peso de la historia" se atreve a portar los emblemas recién creados, apercibido de "los aires de deserción que se advierten en nuestras filas" (48). De manera que para la selectividad foránea este sistema provinciano es cuando mucho una administración imaginaria, y sin embargo no deja de tener realidad de acuerdo a su circunscrita operación, a esa mínima identidad que compromete la univocidad del modelo de espaciamiento. La nueva provincia, para decirlo en los términos de De Certeau (2000: 118), "constituye una falla en el [discurso] que satura de significación los lugares y los reduce al punto de volverlos "irrespirables", autorizando "la producción de un espacio de juego en un tablero analítico y clasificador de identidades".

El requisito imprescindible que permite tal falla y, más todavía, que funda la diferencia, es el carácter específico de una actividad codificadora, en este caso supeditada al valor de lo local. Desde la primera declaración discordante, el sistema se irá asentando en una experiencia centrípeta del mundo, que organiza los estímulos según toquen o no toquen al espacio geográfico inmediato. Los hechos reales serán por consiguiente reales a la medida de la provincia; "real" y "local" como significaciones sinónimas. Ningún acontecimiento podrá en adelante plasmarse como tema si no remite a la especificidad del código; y al revés: ningún acoplamiento se regis- 
trará si no engrana con los campos programáticos que el sistema dispone para diversificar sus referencias. Es así como Cifuentes, Meneses y Plasencia productivizan su malestar en la nación.

Tras el acto fundacional del 18 de septiembre, otras tres declaraciones vienen a suplementar la cristalización de la diferencia provinciana. Acaso más que nunca, la diferencia es en esta oportunidad algo largamente diferido. A la provincia de Coelemu la relevan la "República Independiente de Coelemu", la "República Popular Latinoamericana de Coelemu”, y en las postrimerías de la novela un reino cuyos ducados y condados se prorratean los ya conocidos miembros del triunvirato 7 . Para la mirada extrasistémica cada una de tales refundaciones adolece de un rasgo epigonal. Su sentido -como ha señalado Nelly Richard a propósito de las culturas periféricas y particularmente las "de provincias" - se agota al considerarlo un mero "reflejo pasivo", un "rebote" o un "desfase" que debe reabsorberse y superarse por el "ritmo expansivo de la racionalidad metropolitana" (Richard, 1989: 40). Los fundadores, vistas así las cosas, sólo estarían reaccionado con tardanza a los hechos que en el texto se inician con el Frente Popular y concluyen en los días del golpe de Estado del 73. Cada denominación se oye entonces como un eco distante de lo sucedido en el centro, una réplica microcósmica y por lo común deformada del acontecer modélico, tal como Cifuentes mismo lo ratificaría al exponer su posición sobre la campaña presidencial freísta: "Las soluciones que la administración ha dado y seguirá dando [...] son soluciones de parche. Necesitamos una verdadera revolución, pero una revolución en libertad" (39). Todo este cuadro, ceñido hasta el instante a una clase de modernidad atenuada y vicaria, se recompone si la vara que lo mide es la del sistema local. Dentro de él, sentencias como la anterior de Cifuentes nada restan a una actuación diferenciada. Sea la Unidad Popular, sea la dictadura de Pinochet, sea el segundo ascenso de Ibáñez, cualquier dato de las afueras es reconstruido a una escala que ya no puede ser tildada de buenas a primeras como remedo. Para la ínfima catadura del sistema, el mundo existe porque primero existe la provincia, y a los intereses de ésta deben subordinarse los temas posibles. De ahí que "La

\footnotetext{
${ }^{7}$ Una novela de temática similar, publicada posteriormente a la de Gallardo, es Un adiós al descontento, de Eugenio Mimica (1991). En ella se narran los afanes por fundar en territorio magallánico la "República Independiente de Meridionía”, en pugna con un Chile centralizado al que los autonomistas llaman "Administrativa".
} 
República de Chile" marche a un "ritmo diferente del ritmo al que quería marchar la República Popular Latinoamericana de Coelemu” (93), o que en el paroxismo independentista se decrete "el principio de no intromisión en los asuntos internos" de la "Madre Patria” (117).

Impedir que al descarte de las problemáticas nacionales sobrevenga un total encapsulamiento, es la tarea que enfrentan los campos programáticos, principalmente dos: la tradición y el progreso. La tradición escoge del entorno aquello que sirve al refuerzo de una cultura local (producción de pasado), y el progreso se acopla con las ofertas que favorecen a una economía también local (producción de futuro). El progreso de Coelemu determina la afiliación a un movimiento político o la simpatía por un candidato a la presidencia, en tanto que la tradición coelemana transforma al bolero en su baile típico (63) y proscribe la poesía de Nicanor Parra por sus insultos contra la Cordillera de la Costa $(56)^{8}$.

\section{Descentralizar / Recentralizar}

La complejidad interna del espacio provinciano presenta otras manifestaciones en el nivel de las escalas y los puntos de vista. El espacio experimenta procesos de estiramiento y fragmentación, producto de los cuales el centro deviene orden concéntrico y la periferia una constelación descentrada. En vez de un único centro, aparecen diversos centros de magnitud gradualmente inferior, o superior dependiendo de la perspectiva. Coelemu, por ejemplo, es en tal sentido secundario respecto de Chillán, como Chillán lo es de Concepción y Concepción de Santiago. Pero al invertir el foco el propio Coelemu secundariza a otros pueblos, al convertirse en capital de la nueva provincia. Los jóvenes no ambicionan la modernidad de la metrópoli nacional, sino la de algunas ciudades cercanas, y Guariligüe, pese a ser una "aldea digna", no califica para subir de estatus (18). Esta disposición en círculos dotados de progresiva centralidad va acompañada contradictoriamente de un despliegue horizontal que impulsa la entrada al texto de

\footnotetext{
${ }^{8}$ La lectura que Ignacio Valente hizo de este texto se titula precisamente "Viva la Cordillera de la Costa”. El crítico desestima la novela por originarse en "una ocurrencia demasiado obvia y casi infantil como centro argumental" (Valente, 1987).
} 
una toponimia más profusa. La provincia se dilata hasta romperse, y los fragmentos resultantes son los que dan pábulo al recorrido y al contraste. Cifuentes, Plasencia, Meneses y sus familias se desplazan por el interior del espacio local: a Hualqui, donde se miden con otra sospechosa facción autonómica; a Tomé, donde se sopesan las bellezas del paisaje; y a Cobquecura, donde se leen poemas dedicados a Buchupureo, Treguaco, Taucú y San Carlos ${ }^{9}$.

Habiéndose procurado una autoorganización sistémica, el espacio inmutable comienza a apartarse del curso nacional que ha padecido como imperativo metropolitano. Los nuevos trazados, como puede apreciarse, des-centralizan y re-centralizan simultáneamente. Su diseño identitario presagia las dinámicas que a juicio de Martín-Barbero se movilizan ante la "amenaza” globalizadora: "alucinación” de las pertenencias básicas, resistencia implosiva, "afiebrada búsqueda de sentido" (2000: 31). El sistema provinciano, la república coelemana, necesita de constantes reexámenes y refuerzos, y acaso sea esta inflación autorreferencial la que imante devaluaciones como la del sociólogo Manuel Rodríguez (2005), para quien el provincianismo constituye una "mentalidad" regionalista de "menor monta": "un conjunto de hábitos intelectuales" sustentados en el apego al territorio, en la costumbre, en el recelo frente a lo extranjero, en una mirada esencialmente corta de horizontes. La novela de Gallardo no excluye la posibilidad de una lectura disvalorizante parecida a la de Rodríguez: el actuar desmesurado, la descoincidencia entre el código del sistema y los del entorno podrían ser percibidos tan sólo como un equívoco risible, cuestión que hasta Gaspar Cifuentes desliza en las páginas finales del relato: “¿no habremos estado hueveando, Meneses?” (123). Pero valga repetir que aun en tal caso el código local seguiría afirmándose y mostrando su lógica interna. La nueva provincia no termina de establecer, ni en el discurso del narrador, ni en el desarrollo de los acontecimientos, un modelo único y fatal de espaciamiento, una verdad definitiva y trascendente, capaz de

\footnotetext{
${ }^{9}$ Como se dijo al principio, los trazados geográficos anómalos están presentes también en otras obras de Gallardo. En Historia de la literatura, por ejemplo, se describen modelos clasificatorios y recorridos por el país que resultan imprevisibles bajo el condicionamiento centro-periferia. En Cátedras paralelas, según lo ha mostrado Mauricio Ostria (1985: 114118), se parodian los "estereotipos formales" del criollismo en relación con los espacios provincianos, mostrando "la consciente deflación de un verosímil" reducido a su condición de "signo", "letra" o "texto".
} 
cancelar la autonomía ejercida por el sistema sobre el control de su propia selectividad.

\section{Conclusión}

A través del examen de las codificaciones locales rastreables en La nueva provincia, se puede afirmar que la novela de Gallardo da cuenta de una forma distinta de espacializar y de construir la realidad, logrando que el mundo se integre a un movimiento centrípeto cuyo eje es ahora la antigua periferia. Para esta experiencia, los estímulos externos sólo existen cuando comprometen al espacio inmediato. Simultáneamente, se bosqueja un mapa chileno desmesurado, donde hay círculos concéntricos en lugar de una sola capital hegemónica, y un despliegue de topónimos heterogéneos en lugar de una periferia uniformizada y degradada. Cifuentes, Meneses y Plasencia, los líderes de la República de Coelemu, hacen de su malestar en la nación una oportunidad para ir desestabilizando los posicionamientos que nacen del estatus geográfico. Aquel tópico que sanciona la absoluta inferioridad provinciana -y que en Chile acaso venga reiterándose desde la burlesca caracterización decimonónica del coquimbano o el talquino de visita en Santiago-, es reescrito entonces como un uso entre otros posibles, un uso transformable o reemplazable por más difundido que se halle. Aun cuando el sistema sea aquí de proporciones mínimas, su operar diferenciado no deja de remitir por lo demás a ciertas cartografías críticas y modos de organización no centralistas, que tampoco son extraños a la tradición foral, sociocrática, advertida por algunos historiadores (Salazar, 2011; Cartes, 2014) a propósito de las ciudades y los pueblos autogobernados que se emplazaron en este mismo territorio antes de su más o menos represiva nacionalización.

\section{Referencias}

Achugar, H. (1996). Repensando la heterogeneidad latinoamericana (a propósito de lugares, paisajes y territorios). Revista Iberoamericana, LXII, 176$177,845-861$.

Alonso, M. N.; Mestre, J.C.; Rodríguez, M. y Triviños, G. (1989). Las plumas 
del colibrí. Quince años de poesía en Concepción. Santiago: INPRODE/CESOC.

Bajtin, M. (1989). Teoría y estética de la novela. Madrid: Taurus.

Cartes, A. (2014). “Un gobierno de los pueblos...” Relaciones provinciales en la Independencia de Chile. Valparaíso: EUV.

Césaire, A. (2006). Discurso sobre el colonialismo. Madrid: Akal.

Culler, J. (1984). Sobre la deconstrucción. Madrid: Cátedra.

De Certeau, M. (2000). La invención de lo cotidiano. 1 Artes de hacer. México: Universidad Iberoamericana.

Espinosa, J. (1928). La señorita Cortés-Monroy. Santiago: Imprenta Universitaria.

Gallardo, A. (1982). Historia de la literatura y otros cuentos. Concepción: Andalién. . (1985). Cátedras paralelas. Concepción: Lar. . (1987). Obituario. México: FCE. (2 $2^{\mathrm{a}}$ ed., Santiago: Overol, 2015). . (1987). La nueva provincia. México: Fondo de Cultura Económica. ( $2^{\mathrm{a}}$ ed. Santiago: Liberalia, 2015).

. (2000). Las estructuras inexorables del parentesco. Concepción: I. M. de San Pedro. . (2007). Tríptico de Cobquecura. Santiago: Liberalia.

Gramsci, A. (1967). Cultura y literatura. Barcelona: Península.

Hutcheon, L. (2000). Teoría a politica da ironia. Belo Horizonte: UFMG.

Latcham, R. (1930). Las novelas de Januario Espinosa. Atenea, 14, 75-79.

López Martínez, M. I. (2007). El tópico literario: teoría y crítica. Madrid: Arco/Universidad de Extremadura.

Luhmann, N. (2000). La realidad de los medios de masas. Barcelona: Anthropos/Universidad Iberoamericana.

Martín-Barbero, J. (2000). Globalización y multiculturalidad. En. M. Moraña (ed.), Nuevas perspectivas desde/sobre América Latina: el desafío de los estudios culturales (pp. 17-29). Santiago: Cuarto Propio.

Mimica, E. (1991). Un adiós al descontento. Santiago: Mosquito.

Ostria, M. (1985). Cátedras paralelas: Neocriollismo, intertextualidad y la despiadada verdad histórica. En A. Gallardo, Cátedras paralelas (pp. 103120). Concepción: Lar.

Richard, N. (1989). Modernidad, postmodernismo y periferia. Ponencia presentada en el Coloquio Latinoamericano "Modernidad y Provincia" organizado dentro del marco de la Bienal de Trujillo (Perú), Noviembre 1987. En N. Richard, La estratificación de los márgenes (pp. 39-48). Santiago: Francisco Zegers Editor.

Rodríguez, M. (2005). Provincianismos y localismos: Introducción a la mentalidad provinciana. Disponible en http://paradigmasblogspot.com. 
Salazar, G. (2011). En el nombre del Poder Popular Constituyente (Chile, Siglo $X X I)$. Santiago: Lom.

Silva Castro, Raúl (1928). La señorita Cortés Monroy, por Januario Espinosa. Atenea, 5, 427-429.

Torres Nafarrate, J. (2000). In memoriam. En N.Luhmann, La realidad de los medios de masas (VII-XXIV). Barcelona: Anthropos/Universidad Iberoamericana.

Valdés, A. (2007). Andrés Gallardo: Los yacimientos de la lengua. Prólogo a Tríptico de Cobquecura. Santiago: Liberalia.

Valente, I. (1987). Viva la Cordillera de la Costa. El Mercurio, E3, 11-X-87.

Verdugo, M. (2010). Topofobias. La construcción del paisaje provinciano en la narrativa chilena. Revista de la Escuela de Arquitectura de la Universidad de Talca, 4, 98-105. 